\title{
A Consensual Inquiry of Teachers' Responses to Classroom Situations: Implications for School Counselors
}

\author{
Jeffrey M. Warren \\ University of North Carolina at Pembroke \\ Gretchen G. Robinson \\ University of North Carolina at Pembroke
}

\begin{abstract}
Although often overlooked by school leaders, teacher emotions are key factors that impact classroom climate and therefore educational outcomes and student success. We use a framework grounded in rational emotive behavior therapy and social cognitive theory to explore teachers' perceived thoughts, emotions, and behaviors in response to common classroom situations. The consensual qualitative research methodology was used to analyze data collected from 21 elementary school teachers. Findings suggest that psychosocial barriers exist among teachers who undermine effective instruction and classroom climate. Implications for school counselor practice are discussed.
\end{abstract}

Keywords: teacher beliefs, classroom climate, student success, school counseling, teacher effectiveness

\section{Introduction}

A main goal of school-based leaders is to support the development of learning environments conducive to student success (American School Counselor Association, 2012). As noted by J. M. Warren $(2013,2018)$, teacher emotions, while often overlooked, are a critical determinant of academic achievement. Teachers model an array of emotions and behaviors throughout the school day (Harvey, Bimler, Evans, Kirkland, \& Pechtel, 2012). The psychosocial responses of teachers influence students' confidence, willingness to learn, and classroom success (Steuer \& Dresel, 2011).

$\mathrm{Fu}$, Lin, Syu, and Guo (2010) found teachers experience most frustration and anger between the hours of 10 a.m. and 2 p.m. These emotions detract from learning opportunities during a prime academic time of the school day. In a study conducted by J. M. Warren (2013), teachers indicated that healthy emotional responses positively influenced the climate in their classrooms. Teachers reported that relationships with students were stronger and students were more engaged in instruction; a study by Hagenauer, Hascher, and Volet (2015) yielded similar results. Sutton, Mudrey-Camino, and Knight (2009) suggested teachers are typically comfortable with displaying positive emotions and often reap benefits when engaging in classroom management. However, teachers lack confidence in their ability to reduce and manage negative emotions.

The purpose of this study was to explore teachers' responses to common classroom situations to gain a better understanding of their thoughts, emotions, and behaviors. This study was guided by one main research question: What are teachers' psychosocial responses to common classroom situations? The first author aimed to examine variables such as cognitions (e.g., efficacy beliefs), emotions, and behaviors such as seeking support. The consensual qualitative research (CQR) methodology proposed by Hill, Thompson, and Nutt Williams (1997) was used in this study. Domains and categories 
emerging from a consensual analysis of the data collected are presented. Discussion and implications for educational practice are offered.

\section{Method}

CQR is a research methodology grounded in several qualitative traditions. Key aspects of CQR are derived from grounded theory, phenomenology, and comprehensive process analysis. This methodology allows for semistructured interviews, a team approach, and the exploration of similarities across participants (Hill et al., 2005). The goal of CQR is to highlight participants' views and perspectives through a consensual analysis of data (Hays \& Wood, 2011).

Considerations for consensus are embedded throughout each aspect of the methodology. Researchers strive to reach consensus or agreement on how to accurately describe participants' perspectives. During data analysis, domains, core ideas, and categories are consensually developed to capture and conceptualize the experiences of participants. Domains or topics used to group and organize data are often developed at the outset of the analysis (Hill et al., 2005). Within each domain, researchers summarize the data using clear and concise abstracts also known as core ideas. Through a crossanalysis of cases or participants, categories are developed that serve to establish common themes (Hill et al., 2005). Researchers engage in collective efforts with team members and participants to ensure findings accurately represent the data collected.

The first author elected to utilize CQR in this study for several reasons. First, CQR was selected because it allows researchers to engage in a consensual process at all stages of data analysis, thus minimizing the effects of bias. In turn, accurate descriptions of participants' views rather than quantitative outcomes are gleaned from the data (Hill et al., 2005). In CQR, research team members are encouraged to view participants as experts and become intimately familiar with the data. CQR also offers researchers the ability to consider commonalities across participants in broad terms. Given the consensual and accommodating nature of this research methodology, CQR offered a viable option for understanding teachers' responses to common classroom situations.

\section{Participants and Procedures}

The participants in this study were 21 elementary teachers in a rural school system in the southeast United States. Seventeen (80.90\%) participants held a bachelor's degree, while four (19.04\%) held a master's degree. The sample comprised 20 females and one male. Participants' teaching experience ranged from less than a year to more than 20 years $(M=10.04$ years). Three $(14.28 \%)$ participants taught kindergarten, two (9.52\%) taught first grade, five (23.80\%) taught second grade, four (19.04\%) taught third grade, two (9.52\%) taught fourth grade, and one (4.76\%) taught fifth grade. Four (19.04\%) participants taught in alternative classroom settings (i.e., special education, remediation).

Prior to the study, the first author obtained approval from the school system's superintendent and director of student services. The first author met with the teachers and provided an overview of the study once permission was obtained from the school's principal. Teachers voluntarily agreed to participate in the study. Data collection occurred after approval was obtained from the university's institutional review board.

The Classroom Scenarios Questionnaire (CSQ) was developed by the first author and served as the main mode of data collection in this study. The CSQ is an online questionnaire designed to explore teachers' perceived reactions to common classroom situations. This measure is based on two theoretical frameworks: rational emotive behavior therapy (REBT; Ellis, 1962) and social cognitive theory (Bandura, 1986). 
The questionnaire consists of five classroom scenarios that include a prompt and an image. Participants were asked to look at the image, read the prompt, and consider themselves in each situation. Scenarios include (a) a reading center that students failed to clean after use; (b) a blackboard in which a student anonymously wrote, "U r stupid"; (c) a student walking around the classroom disturbing others during a class activity; (d) working with a group of disengaged students who have failed to meet standards; and (e) a student who left his book bag in the middle of the classroom floor. Each scenario consists of four open-ended questions designed to elicit perceived cognitive, emotive, and behavioral responses. Participants are asked questions such as, "How do you feel?" and "What are you thinking that leads you to feel this way?" These types of questions are designed to explore respondents' perceived beliefs and emotions related to common classroom situations. An example of a question aimed to elicit perceived behavioral responses is, "How will you handle this situation?" Finally, "Does this situation change how well you think you can respond to defiant students?" is an example of a question designed to explore perceived efficacy. Each scenario also offers a text box for participants to provide additional comments. The CSQ takes approximately 20 min to complete.

All participants completed the CSQ after school in a large group setting in the school's computer lab. Participants accessed the CSQ by typing the appropriate URL into their computer's web browser. The CSQ homepage provided instructions for completing the questionnaire. The first author circulated throughout the computer lab and was available for questions as needed. Responses were anonymously submitted online once the participants completed the measure. Completed questionnaires were delivered directly to a secure email account created for the study.

\section{Research Team}

A research team was established to analyze the data collected in this study. The team consisted of two current school counselors and one former school counselor. One of the school counselors was also a licensed professional counselor. A fourth school counselor served as an external auditor for the study. The first author is a National Certified School Counselor and holds a doctorate in counselor education and supervision. The team and auditor were trained in CQR as suggested by Hill et al. (2005). The first author provided the team and auditor with samples of coded data and examples of studies that used CQR as a research methodology. Additionally, the team members and auditor were asked to study Hill et al. (2005) and refer to Hill et al. (1997) for additional reference as needed.

\section{Data Analysis}

The use of domains, identification of core ideas, and the development of categories or common themes across participants are central to CQR (Hill et al., 2005). The research team aimed to reach consensus at each stage of analysis. This consensual process led to key findings based on data collected from the 21 elementary school teachers who participated in this study.

Initially, the research team developed seven domains: (a) irrational beliefs, (b) rational beliefs, (c) healthy emotions, (d) unhealthy emotions, (e) healthy behaviors, (f) unhealthy behaviors, and (g) perceived efficacy. These domains were based on the work of J. M. Warren (2010a, 2010b, 2013), J. M. Warren and Baker (2013), and J. M. Warren and Gerler (2013). The team members were aware that the domains were fluid and the data may warrant the creation, deletion, or modification of domains. As recommended by Hill et al. (2005), the team met to consensually formalize the coding of the domains and to establish brief abstracts of the data, known as core ideas. Through ongoing dialog across several meetings, the team consensually decided these domains were too restrictive and speculative of the participants' responses. The team agreed the analysis should detach from theoretical enmeshment; based on a review of literature, perceived efficacy remained an independent domain. Several of the domains were collapsed and expanded to provide precision and clarity. This 
process led the team to consensually identify four domains: (a) feelings, (b) thoughts, (c) behaviors, and (d) perceived efficacy. The auditor thoroughly reviewed the analysis and agreed with the identification of the domains, yet offered recommendations for slight modification to several of the core ideas developed by the team. The team met to discuss the auditor's feedback and reached agreement on the recommendations. Again, the auditor reviewed and then approved the team's analysis.

Once the analyses of domains and core ideas were completed, a cross-analysis was conducted. The core ideas for every domain were compiled across each case, except for two. Once all categories were established, the research team conducted a stability check using the two excluded cases. During this process, the team examined the core ideas from the excluded cases to determine their fit within the categories. The stability check ensured the identified categories encompassed and represented all core ideas. The development of the categories allowed the team to interpret and elaborate on the meaning of the data (Hill et al., 2005). The auditor provided checks and critiques during the crossanalysis. Based on the success of the stability check and the feedback from the auditor, the team consensually agreed that 11 categories encompassed the core ideas across the participants. The team applied labels to each category to represent the frequency of occurrence. As recommended by Hill et al. (2005), "general" (G) indicated every case (21 cases), half of the cases (10 or 11 cases) were considered "typical" (T), and a few cases (3 to 5 cases) were considered "variant" (V). One or two cases were described using a "rare" (R) label.

\section{Trustworthiness}

CQR inherently addresses critical factors that impact data analysis such as researcher bias and reflexivity (Hill et al., 2005). Trustworthiness and credibility were established through transparency and the consensual nature of the data analysis process. During data analysis, the team frequently participated in meetings based on a formal consensus process developed by Butler and Rothstein (2007). Through constructive dialogue and debate, team members interpreted the data while remaining reflexive or cognizant of their influence on the research process. This process, in conjunction with the use of an auditor, was implemented at each step of analysis to offer an additional layer of dependability. Once a rough draft of the study was complete, five participants were randomly selected to review and comment on the findings. The participants' reviews of the findings yielded no significant concerns.

\section{Results}

At the conclusion of the data-collection phase, participants had submitted a total of 105 responses to the scenarios. These data are represented below through four organized groups also known as domains: (a) feelings, (b) thoughts, (c) behaviors, and (d) perceived efficacy. Thematic groupings or categories and frequency labels (i.e., G, T, V, R) established during the analysis are provided. Verbatim responses from which the core ideas emerged were extracted from the transcripts and included below to further enhance trustworthiness. These responses offer additional insights into the teachers' emotions and the climate in their classrooms.

\section{Feelings}

Participants expressed a variety of emotions based on the classroom situations presented in the CSQ. The cross-analysis identified two categories related to feelings: negative (G) and positive (R). These categories provided meaningful understanding of the feelings experienced by the participants. Participants indicated they would experience negative emotions such as frustration, irritation, and anger toward the classroom scenarios. For example, one participant described her feelings by stating, "I have many emotions. For one, I am upset that they did not follow directions and clean up 
after themselves, but I am also disappointed that no one picket [sic] up or straightened up." Another participant described her emotional response by stating, "I feel upset and frustrated that the student is not following directions and that is distracting other students who are trying to learn." In response to another scenario, one participant stated, "I am a little irritated. We always go through the same process everyday." Still another participant indicated feeling "frazzled because morning time is when children are coming to you with different things they brought from home and important papers we are collecting."

Participants also suggested they experienced positive emotions to the adverse classroom scenarios. For example, one participant replied, "I feel great that the students used so much of the material. I just wish they had enough time to put it back in a neat order." Another participant responding to a scenario said, "I feel okay because most of the materials are up off the floor." These types of responses were rare compared to the more commonly experienced negative emotions.

\section{Thoughts}

Participants offered several different types of thoughts about student behavior and the scenarios on the CSQ. The categories that provided a meaningful conceptualization of the participants' thoughts are realistic $(\mathrm{V})$, assumptive $(\mathrm{T})$, and demands $(\mathrm{T})$. Realistic thoughts provided concrete, objective details of the situation and were not demanding. One participant expressed her thoughts about a scenario by stating, "It [reading center] is disorganized and out of sorts and I don't like it that way." Another participant describing a scenario indicated, "The student is not following directions, not getting his work done and he is also interrupting others and drawing them off task." These thoughts describe situations in verifiable and objective ways.

Assumptive thoughts are inferential in nature. In these cases, teachers formulated thoughts that are subjective or value laden. For example, in response to one scenario a teacher thought, "Maybe I did something to upset a child and they are mad at me at that moment so they wrote how they were feeling on the board." Another participant described thinking, "The student did not take enough time to put everything back neatly. They may have rushed or did not know the importance of keeping everything neat and orderly." These thoughts lack objectivity and are rooted in uncertainty.

Demands are thoughts that are rigid and dogmatic. These thoughts may include words or phrases such as "should," "need to," or "must." For example, when completing a scenario one participant thought, "They left it [reading center] in an unacceptable manner. They did not put items back neatly and need to try again if they want to keep the privilege of using them." Another participant suggested, "These students should know how to keep the classroom in order and safe after being in my classroom for 134 days." Teachers frequently made assumptions and demands; realistic thoughts were much less common.

\section{Behaviors}

Three categories provided meaningful understanding of the participants' behavioral responses to classroom situations. These categories include management $(\mathrm{G})$, communication (T), and support (V). Management included behaviors such as calling parents, administering consequences, and offering rewards in attempts to maintain command of the classroom. For example, one participant indicated,

They [students] would have to follow the routine before they could do anything else first. They probably wanted to hurray [sic] and get finished. The boy on the computer would not be allowed to go to the computer until he had his things put away, and the boy at his seat would have to go put his things away also. 
Another participant emphasized both consequences and positive reinforcement by suggesting,

If the same students come in daily not following the routines, then there would need to be consequences for them. There should be some type of reward for those who do follow the routines each day. I would remind them that their day would probably go better if it has a better start.

Communication was identified as the verbal dissemination of messages and statements to students. Communication included reminding students, engaging in conversation with students, and asking them questions. For example, one participant suggested, "I will tell them that they cannot start their work if their belongins [sic] are not placed where they are supose to be." Another participant described,

I would talk to these students. They are the first 2 in the room, so if I talk to them now, there should be little chance of upsetting them. After that, I may talk to all of my students about the morning routine, reminding them what needs to be done. I would also have them go back to using the "Morning Work" task list in the morning.

The last category, support, is described as "hands-on" behaviors that aid or assist students. Participants offered support by working collaboratively, helping students practice, and modeling appropriate behaviors. One participant described,

I would continue to try to find new ways to get through to them. I would also make sure the parents are working with them at home and give them some different strategies they can try with their child at home.

Another participant suggested, "I would move the table so the students would not be distracted by what is going on outside the window. I would also start finding some easy games to build up their confidence." In response to a scenario involving a student out of his seat, one participant suggested, "I would probably go to the student, take him or her by the hand and gently walk them to their seat. Then, I would help them find what they need to do and help them get started with it." Participants were inclined to respond to situations using classroom management strategies rather than emphasizing the importance of communication and support.

\section{Perceived Efficacy}

Using the scenarios presented on the CSQ as mediating factors, participants elaborated on their perceived efficacy related to student engagement, instructional practices, and classroom management. The participants offered a variety of thoughts that appeared to demonstrate their perceived efficacy in these situations. Participants indicated their perceived level of efficacy would not change based on the outcomes of these situations. The categories that provided meaningful insight into the participants' efficacy beliefs related to the classroom scenarios presented are realistic (V), assumptive (T), and blaming/demanding (T). Realistic thoughts provide concrete, objective details of the situation and were not dogmatic. For example, one participant indicated her perceived efficacy would not waiver as a result of the situation. She remarked, "Little kids need lots of reminders." In response to a separate scenario, another participant confirmed her sense of efficacy by stating, "No, I think that procedures, like picking up a center area, need to be practiced. Students are not perfect and it takes time and rehearsal to get it correct."

Assumptive thoughts are essentially guesses or hypotheses participants had about students or the situations. These thoughts are subjective and have little or no merit. For example, one participant indicated her perceived efficacy would not fail by stating, "No, there will always be issues because some children are simply avoiding the work they do not want to complete. It takes time to get a child 
to understand that their behavior affects others." Another participant indicated their perceived efficacy would not waiver by emphatically stating, "No! Kids will do things just to draw attention to themselves.” Still another participant remarked,

No, because all students are going to be defiant at one time or another. Those students that don't do their homework are defiant in their own way, so no I don't think that we, as teachers, can let one situation define how we respond to students whether defiant or not.

Self-blaming/demanding is defined as rigid, inflexible thoughts that may imply negative personal fault. For example, one participant described a situation's impact on her perceived efficacy by stating,

Yes. It makes me feel like I have to spend too much time and energy teaching a child to obey rules. This takes the focus off of his learning and the learning of the others. I feel that listening and following directions should have been taught prior to his primary school years.

Another participant stated, "Yes, I probably should be more stern, but if it is not effectiving [sic] the students learning again choose your own battles." A different participant indicated, "Yes. I should have reinforced my rules and expectations the first time they were not followed." Efficacy beliefs were routinely based on assumptions and demands, although infrequently realistic.

\section{Discussion}

The psychosocial characteristics of teachers shape classroom climate, a contributing factor of student success. Findings from this study suggest teachers readily maintain thoughts and emotions that are not conducive to ideal learning environments. Teacher behaviors, while well intentioned, are often misguided and tainted by thoughts and emotions, findings similar to those of J. M. Warren (2013), J. M. Warren and Robinson (2015), and J. M. Warren and Hale (2016).

Participants experienced three types of thoughts when responding to classroom adversity on the CSQ. Rather than focusing on the observable, teachers frequently made assumptions. Assumptions lead to inaccurate judgments of student behavior as well as undue stress, thus hindering studentteacher relationships (Chang, 2013). Participants also reported thoughts consistent with demands. However, it is difficult to determine if these thoughts are true demands (i.e., rigid, dogmatic) as described by Ellis (1962) or preferences erroneously stated as demands. Spoken language can often impede the identification of absolute and nonabsolute demands (Dryden, 2014). As a result, teachers who verbalize their thoughts during classroom interactions may appear dogmatic and unempathetic to the plight of their students. The expression of realistic thoughts illustrated the potential for teachers to interpret situations objectively. Objectivity can reduce the opportunity for bias and stereotyping. Nonetheless, teachers appear to incorporate a combination of realistic, assumptive, and demanding thoughts when assessing adverse situations. This finding is consistent with the theoretical propositions of REBT (Dryden, 2014; Ellis \& MacLaren, 2005)

Participants often provided thoughts in response to questions designed to elicit feelings or emotions. Teachers may not consistently differentiate between thoughts and emotions and fail to realize these are two separate psychological processes. When teachers did report emotions they were frequently negative (e.g., upset, stress, anger). Frustration was identified more than any other emotion. Depending upon the intensity, this emotion is considered either healthy or unhealthy according to Dryden (2014). In these cases, teachers did not list behaviors that would indicate extreme frustration. Regardless of intensity however, when teachers are frustrated instruction is negatively affected (J. M. Warren, 2018; J. M. Warren \& Robinson, 2015). 
Teachers also described other emotions such as annoyance and disappointment. While these emotions are consistent with healthy negative emotions, participants may have unintentionally misidentified their emotions (Dryden, 2014). For example, a teacher may have felt angry about a situation yet identified their emotion as annoyance. Alternatively, teachers may have purposefully understated their feelings if they viewed disappointment as a more professionally appropriate emotion than anger. During actual classroom situations, teachers may experience dissonance as they navigate their true feelings and perceived need to respond in a professional manner. This incongruence and lack of authenticity can hinder the quality of instruction.

The majority of participants suggested their perceived ability would not waiver if faced with these situations. This finding contradicts an assertion by Tschannen-Moran, Woolfolk Hoy, and Hoy (1998) that teacher efficacy beliefs typically fluctuate throughout the day based on classroom experiences. Assumptive and realistic thoughts related to perceived ability were consistently expressed by participants, which suggests teachers maintain stable efficacy beliefs. However, self-blaming and demanding were commonly described by participants whose efficacy beliefs appeared to waver. This subtle distinction in beliefs is consistent with research conducted by J. M. Warren (2010a) and J. M. Warren and Dowden (2012), which suggests a correlation exists between irrational beliefs (i.e., selfblame) and efficacy beliefs. More recently, J. M. Warren and Hale (2016) further explicated the negative impact of efficacy beliefs on teacher emotions and behaviors.

Teachers in this study did not clearly demonstrate empathy or express considerations for students' emotions, cultural background, or lived experiences. These omissions may represent teachers' lack of cultural sensitivity and an emotional disconnect with their students. Teacher empathy is not widely studied (see Arghode, Yalvac, \& Liew, 2013; Swan \& Riley, 2015), however, these collective factors may contribute to the inability of teachers to effectively maintain optimal learning environments and deliver culturally responsive pedagogy (C. A. Warren, 2017). Culturally responsive and empathetic teachers are intentional in the use of instructional strategies that address diverse cultural, linguistic, and experiential backgrounds of their students (Robinson, 2010, 2016). Teachers should not overlook the importance of students' backgrounds and cultures (van Tartwijk, den Brok, Veldman, \& Wubbels, 2009), but should take this into account while understanding how their own beliefs and biases affect their teaching. By taking a vested interest in students, teachers are afforded the opportunity to gain insight into their lives and assist them in developing academically, socially, and personally.

Finally, participants failed to indicate that they would seek support from student support service personnel such as school counselors. This observation suggests that teachers may not consider support services such as consultation or collaboration key functions of school counseling or other support service personnel. Nonetheless, school counselors are ideally positioned to work collaboratively with teachers to develop positive classroom climates as outlined in the American School Counselor Association (2012) national model. These efforts support teachers in the delivery of effective instruction and consistent classroom management which will facilitate inviting classrooms primed for student success.

\section{Limitations of the Study}

There are several limitations of this study. First, CQR recommends the use of interviews to gather data sets of rich lived experiences. Hill et al. (2005) cautioned against the use of "too many scripted questions" (p. 199) but expressed the need for reliable interviewers who question and probe with fidelity. This study utilized a semistructured online questionnaire, thus the need for reliable interviewers was unmet. While participants appeared forthcoming and the first author believed data saturation occurred, the instrumentation may have hindered the depth of the data collected. With slight modifications, the CSQ could have yielded quantitative data. Use of Likert scales would have 
allowed the participants to indicate the intensity of their emotions and thoughts. For example, a question such as, "On a scale of 1 to 10, how strong is your emotion?" could offer additional insight into teacher emotions. Although questionnaires are not recommended in CQR, Hill et al. (2005) supported the use of nontraditional means of data collection. The CSQ is efficient, cost effective, and discreet. As a result, participants were able to disclose thoughts, emotions, and behaviors to sensitive situations anonymously and in a timely manner.

\section{Implications}

The findings of this study suggest that teachers can respond to common classroom situations in ways that impede the development of positive classroom climates. Schools leaders, including school counselors, are encouraged to offer services that support teachers in ways that positively impact instructional practices and school climate. It is critical that teachers learn to implement strategies that foster relationships, promote positive classroom climates, and increase instructional effectiveness.

School counselors are encouraged to consider ways in which indirect student services are designed and marketed to teachers. Based on the findings of this study, school counselors should aim to create atmospheres that encourage teachers to engage in help-seeking behaviors. Establishing professional working relationships can solidify the school counselors' role in empowering teachers to promote student success. When planning, organizing, delivering and evaluating an intervention, school counselors must remain transparent, because some teachers may consider aspects of these stages invasive. J. M. Warren and Robinson (2015) suggested that ensuring intent and gaining trust are necessary to obtain "buy-in" and cooperation from teachers. These drivers are paramount in the implementation of new methods or shifts in education (J. M. Warren, 2018).

A key indirect student service school counselors provide is consultation. As consultants, school counselors work with teachers (consultee) to support students or groups of students. Consultation is a viable means of supporting teachers' classroom efforts to provide optimal learning environments. Rational emotive-social behavioral (RE-SB) consultation proposed by J. M. Warren (2010a, 2018) integrates REBT (Ellis, 1962) and social cognitive theory (Bandura, 1986) to offer school counselors a theory-driven, evidence-based model of consultation. This model utilizes principles and concepts from both theories to form a cohesive framework that addresses psychosocial barriers that impede the ability of teachers to work effectively with students.

Large group, small group, and individual RE-SB consultation serve as platforms for promoting teacher effectiveness (see J. M. Warren, 2018; J. M. Warren \& Baker, 2013). Through consultation, teachers can gain greater awareness of their thoughts, feelings, and behaviors that impact student success. Further expansion of teachers' emotional vocabulary can aid in correctly labeling and managing their emotions as well as using emotional language effectively when interacting with students.

As the findings of this study suggest, efficacy beliefs and demanding or irrational thoughts are problematic when teachers erroneously base them on unreliable sources of information. Teachers maintain stigmas, stereotypes, and biases that thwart empathy and negatively influence classroom climate. Through RE-SB consultation, school counselors can work in tandem with teachers to dissect these beliefs, develop rational coping statements, establish functional responses, and become more culturally competent. Teachers must address the core issues of their emotional and behavioral responses rather than simply surface acting, or concealing true emotions, as noted by Barber, Grawitch, Carson, and Tsouloupas (2011). 
School counselors are encouraged to explore innovative, collaborative strategies for supporting teachers. For example, school counselors can coordinate a "walk-and-talk" consultation during lunch or planning periods. An exercise-based program of this nature allows teachers the opportunity to connect with colleagues, reduce stress, and increase their quality of life (Schuch, Vasconcelos-

Moreno, \& Fleck, 2011). These efforts can have a direct impact on classroom climate and the quality of instruction students receive. Regardless of the services school counselors provide to teachers, they should remain student centered. In other words, school counselors assist teachers in the development or identification of strategies that support student success. In many cases, there are residual effects as well (see J. M. Warren, 2013).

\section{Conclusion}

Teacher emotions as well as classroom climate are largely ignored when describing factors that impact student success. This study suggests that teachers often respond to classroom situations in ways that negatively impact classroom climate and student success. School counselors can play a significant role in promoting healthy classroom climates and student success through the implementation RE-SB consultation. We hope the findings of this study will shed light on the psychosocial responses of teachers and provide school leaders with direction for offering targeted system support.

\section{References}

American School Counselor Association. (2012). The ASCA national model: A framework for school counseling programs (3rd ed.). Alexandria, VA: Author.

Arghode, V., Yalvac, B., \& Liew, J. (2013). Teacher empathy and science education: A collective case study. Eurasia Journal of Mathematics, Science \& Technology Education, 9, 89-99.

Bandura, A. (1986). Social foundations of thought and action: A social cognitive theory. Englewood Cliffs, NJ: Prentice-Hall.

Barber, L. K., Grawitch, M. J., Carson, R. L., \& Tsouloupas, C. N. (2011). Cost and benefit of supportive versus disciplinary emotion regulation strategies in teachers. Stress and Health, 27, 173-187.

Butler, C. T., \& Rothstein, A. (2007). On conflict and consensus: A handbook on formal consensus decision making. Tacoma Park, MD: Food Not Bombs Publishing.

Chang, M. L. (2013). Toward a theoretical model to understand teacher emotions and teacher burnout in the context of student misbehavior: Appraisal, regulation and coping. Motivation and Emotion, 37, 799-817. doi:10.1007/s11031-012-9335-0

Dryden, W. (2014). Rational emotive behaviour therapy: Distinctive features. London, United Kingdom: Routledge.

Ellis, A. (1962). Reason and emotion in psychotherapy. Secaucus, NJ: Citadel Press.

Ellis, A., \& MacLaren, C. (2005). Rational emotive behavior therapy: A therapist's guide (2nd ed.). Atascadero, CA: Impact Publishers.

Fu, C. S., Lin, S. T., Syu, S. H., \& Guo, C. Y. (2010). What's the matter in class? Preschool teachers' emotions expression. Procedia Social and Behavioral Sciences, 2, 4887-4891.

doi:10.1016/j.sbspro.2010.03.789 
Hagenauer, G., Hascher, T., \& Volet, S. E. (2015). Teacher emotions in the classroom: Associations with students' engagement, classroom discipline and the interpersonal teacher-student relationship. European Journal of Psychology of Education, 30, 385-403. doi:10.1007/s10212015-0250-0

Harvey, S. T., Bimler, D., Evans, I. M., Kirkland, J., \& Pechtel, P. (2012). Mapping the classroom emotional environment. Teaching and Teacher Education, 28, 628-640.

Hays, D. G., \& Wood, C. (2011). Infusing qualitative traditions in counseling research designs. Journal of Counseling \& Development, 89, 288-295. doi:10.1002/j.1556-6678.2011.tb00091.x

Hill, C. E., Thompson, B. J., Hess, S. A., Knox, S., Nutt Williams, E., \& Ladany, N. (2005). Consensual qualitative research: An update. Journal of Counseling Psychology, 52, 196-205.

Hill, C. E., Thompson, B. J., \& Nutt Williams, E. (1997). A guide to conducting consensual qualitative research. The Counseling Psychologist, 25, 517-571.

Robinson, G. G. (2010). Culturally responsive beliefs and practices of general and special education teachers implementing response to intervention (RTI) in diverse elementary schools (Doctoral dissertation). Retrieved from ERIC. (ED518463)

Robinson, G. G. (2016). Culturally responsive beliefs and practices of general and special education teachers within a response to intervention framework. Multiple Voices for Ethnically Diverse Exceptional Learners, 16, 22-36.

Schuch, F. B., Vasconcelos-Moreno, M. P., \& Fleck, M. P. (2011). The impact of exercise on quality of life within exercise and depression trials: A systematic review. Mental Health and Physical Activity, 4, 43-48. doi:10.1016/j.mhpa.2011.06.002

Steuer, G., \& Dresel, M. (2011, April). Dealing with errors in mathematics classrooms: The relevance of error climate and personal achievement motivation. Presented at the 91st annual meeting of the American Educational Research Association, New Orleans, LA.

Sutton, R. E., Mudrey-Camino, R., \& Knight, C. C. (2009). Teachers' emotion regulation and classroom management. Theory Into Practice, 48, 130-137.

Swan, P., \& Riley, P. (2015). Social connection: empathy and mentalization for teachers. Pastoral Care in Education, 33, 220-233.

Tschannen-Moran, M., Woolfolk Hoy, A., \& Hoy, W. K. (1998). Teacher efficacy: Its meaning and measure. Review of Educational Research, 68, 202-248.

van Tartwijk, J., den Brok, P., Veldman, I., \& Wubbels, T. (2009). Teachers' practical knowledge about classroom management in multicultural classrooms. Teaching and Teacher Education, $25,453-460$.

Warren, C. A. (2017). Empathy, teacher dispositions, and preparation for culturally responsive pedagogy. Journal of Teacher Education. Advance online publication. doi:10.1177/0022487117712487

Warren, J. M. (2010a). School counselor system support using mental health interventions. The New York State School Counseling Association Journal, 7, 30-39.

Warren, J. M. (2010b). The impact of rational-emotive behavior therapy on teacher efficacy and student achievement. Journal of School Counseling, 8(11). Retrieved from http://www.jsc.montana.edu/articles/v8n11.pdf

Warren, J. M. (2013). School counselor consultation: Teachers' experiences with rational emotive behavior therapy. Journal of Rational-Emotive \& Cognitive-Behavior Therapy, 31, 1-15. doi:10.1007/s10942-011-0139-z 
Warren, J. M. (2018). School consultation for student success: A cognitive-behavioral approach. New York, NY: Springer.

Warren, J. M., \& Baker, S. B. (2013). School counselor consultation: Enhancing teacher performance through rational emotive-social behavioral consultation. In G. R. Walz, J. C. Bleuer, \& R. K. Yep (Eds.), VISTAS online. Retrieved from https://www.counseling.org/docs/defaultsource/vistas/school-counselor-consultation-enhancing-teacher-performance.pdf?sfvrsn=11

Warren, J. M., \& Dowden, A. R. (2012). Elementary school teachers' beliefs and emotions: Implications for school counselors and counselor educators. Journal of School Counseling, 10(19). Retrieved from http://jsc.montana.edu/articles/v10n19.pdf

Warren, J. M., \& Gerler, E. R. (2013). Effects of school counselors' cognitive behavioral consultation on irrational and efficacy beliefs of elementary school teachers. The Professional Counselor, 3, 6-15. doi:10.15241/jmw.3.1.6

Warren, J. M., \& Hale, R. W. (2016). The influence of efficacy beliefs on teacher performance and student success: Implications for student support services. Journal of Rational-Emotive \& Cognitive-Behavior Therapy, 34, 187-208. doi:10.1007/s10942-016-0237-z

Warren, J. M., \& Robinson, G. (2015). Addressing barriers to effective RTI through school counselor consultation: A social justice approach. Electronic Journal for Inclusive Education, 3, 3.

The Journal of Educational Research and Practice provides a forum for studies and dialogue that allows readers to better develop social change in the field of education and learning. Journal content may focus on educational issues of all ages and in all settings. It also presents peer-reviewed commentaries, book reviews, interviews of prominent individuals, and additional content. The objectives: We publish research and related content that examines current relevant educational issues and processes aimed at presenting readers with knowledge and showing how that knowledge can be used to impact social change in educational or learning environments. Additional content provides an opportunity for scholarly and professional dialogue regarding that content's usefulness in expanding the body of scholarly knowledge and increasing readers' effectiveness as educators. The journal also focuses on facilitating the activities of both researcher-practitioners and practitioner-researchers, providing optimal opportunities for interdisciplinary and collaborative thought through blogging and other communications.

Walden University Publishing: http://www.publishing.waldenu.edu 